\title{
How Mining Multinational Corporations Promote Women? Modus Operandi
}

\author{
Nattavud Pimpa (corresponding author) \\ School of Management, RMIT University \\ E-mail: nattavud.pimpa@rmit.edu.au
}

Timothy Moore

The University of Melbourne

Kabmanivanh Phouxay

National University of Laos

Maliphone Douangphachanh

National University of Laos

Outhoumphone Sanesathid

National University of Laos

Received: Feb. 13, 2016

doi:10.5296/jmr.v8i2.9175
Accepted: March 30, 2016

Published: April 1, 2016

URL: http://dx.doi.org/10.5296/jmr.v8i2.9175

\begin{abstract}
The purpose of this study is to investigate approaches to the promotion of the involvement of women in the international mining industry. In order to identify approaches to promote women in international mining industry, the researchers adopted an exploratory, interpretive approach to work with mining MNCs in Lao PDR. We interviewed 10 key participants from two mining multinational corporations in Laos. Gender discourses were developed in order to comprehend 'talk' and 'texts' as social practices as well as the concepts of 'women at
\end{abstract}




\section{Macrothink}

Journal of Management Research ISSN 1941-899X 2016, Vol. 8, No. 2

workplace' from the perspectives of both men and women. The results show that various approaches can be adopted to promote women. They include (1) encouragement of women, (2) promotion of equal opportunity, and (3) celebration of women and diversity. This study also confirms, in traditionally male-dominant industry such as international mining, management requires extra and specific gender-related expert support in order to effectively promote women's participation in the workplace.

Keywords: Gender in Organizations, Workforce Diversity, Gender Equality 


\section{Introduction}

While ideologies of human rights, gender equity and the elimination of discrimination underpin most multinational corporations' employment policies, counter ideologies of gender equity often prevail in practice (McIntyre, 2011). In the case of mining multinational corporations (mining MNCs), they have been striving to adopt business ideologies and developmental practices that promote equality among men and women in the industry. However, it is reported that women in the mining industry still struggle to be at the similar level to men (Mercier and Gier, 2007).

Previous studies (i.e. Yakovleva and Vazquez-Brust, 2012; Schmidheiny, 2006) also confirm that several factors can be attributed to gender disengagement practices among stakeholders in international mining industry such as mining MNCs, local authorities, policy makers, community, Non-Governmental Organisations (NGOs), and local government agencies. The failure to promote engagement among these stakeholders, and existing unstable and weak national institutions, leads to gender-based disadvantages (DeSoto, 2000).

Whilst there is evidence of increasing effective and sophistication developmental activities on gender equity by mining MNCs, there is no clear understanding on various approaches adopted by mining MNCs. Due to their significant economic and social roles and influences, we need to understand how mining MNCs promote gender equality, and integrate women into their operations. More importantly, factors promoting women in international business organisations (such as mining MNCs) must be comprehended in order to support long-term strategies to empower and promote women in this male-dominated industry.

As gender equality in international business is a salient issue, it has been rather difficult for mining MNCs to state unawareness of their contribution in this area. This, however, has not led to constraints on mining MNCs to behave according to norms that would be conducive to mitigate this important issue in the host and home countries.

\section{Literature Review}

\subsection{Women and Mining}

The Workplace Gender Equality Agency (2013) reveals that the percentage of women in global mining industry has increased from $12.6 \%$ in $2004-05$ to $17.0 \%$ in $2011-12$. However, it is still the second most male dominated industry behind the construction industry.

The ideology of male breadwinner in the mining industry, and the reputed toughness of the work that disqualifies women from mining often disintegrated when operations expanded or the supply of labour shrunk, when men required family assistance in the mines, or when these 'masculine' jobs became seasonal and low-paid (Mercier and Gier, 2007). In fact, as recent research in business and gender reveals, women often moved into the diggings and even dominated mining where enterprises were fairly marginal or provided sustenance when men were required or chose to work elsewhere (Mercier and Gier, 2007; Kemp and Owen, 2013).

Previous studies (Pattenden, 1998; Sharma; 2010) show that women can possibly be allowed underground as independent wage earners, or to assist men in the mining industry (fathers 
and husbands). For the most part, however, Mercier and Gier (2007) found that mining became more exclusively associated with men as it became more capitalised and centralised. Concentrated urban, industrial sites typically insisted on a rigid sexual division of labour, but more rural and subsidiary operations involved families or became the domain of women's work.

It was reported that the sexist views faced by women entering the mining workforce often limit career advancement (Gibson and Scoble, 2004; Tallichet, 2000). These issues are significant management issues that mining MNCs need to (1) understand, (2) find ways to mitigate management risks, and (3) improve work conditions. Studies in mining and gender ascertain that masculine norms sustain structural barriers that marginalise women and negatively impact women on household, community and employment relations (Bose 2004 Issues on gender equity in Laos are not that dissimilar from most other countries in Mekong region.

In Laos, women and girls living in rural and remote areas of Laos are often the most disadvantaged. Men are usually described as the heads of the households, representing their families at official meetings (Oxfam, 2014). Many women are illiterate and do not speak the national language used for education (UNDP, 2013). Prevailing social and cultural norms mean women are not confident to give their opinions, and do not demonstrate simple meeting skills such as taking turns to speak out. Therefore, often women cannot participate fully in village development activity processes (Oxfam, 2014). From the international development perspective, Lao rural areas are undergoing rapid transformation and off-farm jobs are helping pull households out of poverty. However, at the same time, this issue also makes women who do not have access to arable land and lack off-farm skills more vulnerable than men (World Bank, 2013).

\subsection{Why Gender in Mining Industry}

Researchers in gender studies argue that gender is socially constructed (Cameron, 1995; Speer, 2005). The social construction of gender as well as the fluidity and dynamics of how gender is achieved in the social and organisational context are not clearly explored. Kelan (2009) also confirms that it is important to comprehend how gender is constructed in various and specific situations. In the context of international mining industry, it is commonly known that this industry is among the most male-dominated businesses, with men holding more than 90 per cent of executive positions (Earnst and Young, 2013).

As mentioned, social and organisational contexts can construct the 'perceptions' of gender among men and women in society. Gender perception can also be explained by 'role congruity theory' (Eagly and Karau, 2002). This theory explains that when women engage in male-dominated roles or behaviours (i.e., aggressive, ambitious, independent, self-confident), such as those in leadership roles or in mining industry, they are evaluated less favourably than their male counterparts. This is because such roles are more stereotypically associated with men (Eagly and Karau, 2002). Typically, people have congruent beliefs about men and leadership, but dissimilar beliefs about women and leadership. This creates similar 
expectations for male leaders, and contradictory expectations for female leaders (Burton and Parker, 2010). In addition, when engaging in the masculine roles and/or male-dominated industry, necessary in those leadership positions, women are evaluated less favourably than men, because such behavior is perceived as less desirable in women than men (Heilman, Wallen, Fuchs, and Tamkins, 2004). That is, women who behave in a confident, aggressive, independent manner are seen as behaving incongruous to their societal gender norm. This creates dissonance and less favorable impressions than their male counterparts given that gender norms suggest males should demonstrate aggressive, confident, and independent behaviour (Burton and Parker, 2010).

\section{Research Questions}

What remain unclear in the literature is how far have mining MNCs gone when it comes to business and organisational strategies to empower women. The gap between the rhetoric and reality of gender and diversity management issues occurs through the assumption that complexity might only be reduced by power structures in organisations - and that vice versa gender and diversity in the international mining industry will be able to unfold by changing these power relations (Kirton and Greene, 2005, p. 242).

\section{Method}

To identify approaches to promote women in international mining industry, the researchers adopted an exploratory, interpretive approach to work with mining MNCs in Lao PDR. This research is based on a case study of two selected organizations. This approach is appropriate for this particular study as little is known, in this regard, of whether gender management is institutionalized and the role played by mining MNCs (Bondy, 2008). As such, in order to capture the experiences and interpretations of relevant actors on gender management, semi-structured interviews stand as an appropriate data collection technique (e.g. Strauss and Corbin, 1998). This technique helps the researchers to focus on language use by key informants as well as contextual and relational aspects expressed by the participants.

The organisations chosen for this study are leading mining MNCs in Lao PDR. Both mining MNCs have been working in Lao PDR for over a decade and have clear policies on gender and business. We selected them because of their policies and practices on gender, corporate social responsibilities (CSR) and employment. In this study, we selected management and gender policy makers and practitioners from both mining MNCs to be interviewed. These are descriptions of participants from each company. For reasons of ethics, these participants are not identified; the two companies are referred to as A and B.

Company A: It is a mid-tier global resources company which explores, develops and mines base metal projects around the world. As a mining MNCs, it is one of the key actors working in South East and East Asia; headquarters in Australia. We interviewed two CSR and operational managers, and three CSR team members. All participants were invited to the researchers by the CSR manager. Both managers from this company are expatriates who previously worked in development and gender for over a decade in various locations (five participants). 
Company B: This mining MNC is a copper and gold producer in Southeast Asia and has a portfolio of organic growth projects in Laos and Chile. The interviews were conducted with two managers (one expatriate male and one local female) who look after various aspects of CSR and community relationship management in different locations in Lao PDR. Three $\mathrm{CSR} /$ community engagement team members were also invited to participate in this study (five participants).

\subsection{Data Collection and Analysis}

Before each interview, all publically available documents related to the company's CSR programs and gender policies were read and analysed to provide additional information on how each MNC presented itself with regard to its CSR and gender approaches and activities. The researchers focused on company-created documents including their websites, company reports, codes of conduct/ethics, performance indicators and case studies. These were used to prepare interviews and to support interview data. Each interview lasted approximately 40 minutes and was conducted face-to-face at each organisation's premises.

Participants were asked to discuss three broad topics: policies on gender policies, gender and employment, and relationships among mining stakeholders. Issues of validity and reliability were addressed at the data collection stage by using digital recordings, and notes taken directly following each interview, that included non-verbal cues or other pertinent information on the interview process itself (Spiggles, 1994).

The researchers transcribed the data together. At this stage, the data were analysed using the open code software package for the analysis of qualitative data. This process of analysis involved reading through transcriptions, noting the similarities in responses and establishing a theme for each of the response categories. Gender discourses were developed in order to comprehend 'talk' and 'texts' as social practices as well as the concepts of 'women at workplace' from the perspectives of both men and women. The focus of language is important at this stage because the concept of 'male' and 'female' at international mining workplace is not a matter of consistent unitary single identities but develops from contradictory and frequently fragmented pieces of discourse (Kelan, 2009). We followed Speer's points (1999) that the analysis of conversation can be a 'superior' way of showing how gender is done in most research. Careful analysis of 'language' and 'tone' of conversation help us to understand their views on women engagement.

\section{Results}

All participants in this study understand links between gender equity and good management. Most of them could identify positive influence on corporate culture when gender-based policies are included in their practices. A good example was illustrated by CSR manager from company A. He pointed that creating environment that promote gender equity is important for the organisation because it will also promote diversity in ideas and practices. Both mining MNCs also invested in improving their policies by conducting regular gender study in order to improve equity aspect of their work culture. From the interviews, we found three approaches that mining MNCs have adopted to empower women in the workplace. 


\section{Approach 1: Encouraging Women}

Both mining MNCs clearly understand that mining is a traditional male dominant industry and may be difficult to attract and retain women to work in mining industry. In their recruitment and employment policies, both mining MNCs encourage women to apply for various positions from the operation of heavy machine, management and administration to supporting roles in the mine. The goal of this approach to gender equity is to minimise differences between women and men so that women can compete as equals. Mining MNC A can link the benefits of encouraging women to diversity and good work environment in mining industry.

"We recognize that diversity is good for new ideas and positive work environment so we try to encourage women to work with us." (Company A)

To encourage Lao women in the industry, both mining MNCs need to guide them to understand their roles, values and contributions to the organisation. This is important because mining MNCs need to play the role of 'the promoter' to encourage women in the organisation. Some keywords under this approach are listed in Table one.

Table 1. Some Keywords/Phrases on Encouraging Women

\begin{tabular}{|l|l|l|}
\hline "women can...." & "female leadership" & "positions for women" \\
\hline "talented female staff" & "women group" & $\begin{array}{l}\text { "women are capable of } \\
\text { working" }\end{array}$ \\
\hline "potential for women" & $\begin{array}{l}\text { "women's advancement at } \\
\text { work" }\end{array}$ & "female champion" \\
\hline "women and training" & $\begin{array}{l}\text { "different types of work for } \\
\text { women" }\end{array}$ & $\begin{array}{l}\text { "we try different ways to } \\
\text { encourage women" }\end{array}$ \\
\hline
\end{tabular}

Some strategies include leadership development program for women, introducing flexible work practices, open discussion on career path with all members in the organisation (both men and women), and assertiveness training for men and women in the organisation. It is also stated in the sustainability report of company B that targeting women to manage the organisation is one of the key business strategies of the company.

"Two major programs are in place to attract and retain female employees. These include flexible working arrangements and a talent pool of senior women in mining intended to target senior appointments to improve the gender imbalance and informally extend an internal network of women." (Company B)

Encouraging women is an effective approach because it convinces women to believe in their power and contributions. Participants from both mining MNCs confirmed that, given that Lao women are usually in a disadvantaged position in the workplace compared to Lao men, encouraging women via formal and informal corporate channels implies explicit attention to women's needs and perspectives. Traditional ways of discouraging women in mining industry may persist. Hereafter, it is important for mining MNCs to make sure that men also play roles in encouraging women in the corporate. 


\section{Approach 2: Promotion of Equal Opportunity}

Mining MNCs in this study also focus on removing structural barriers that impede women to learn new skills, to be promoted, and to lead the organisation. Equal opportunity at workplace was mentioned by almost all participants in the study as the key to promote long-term gender equality in this industry. Both companies in this study insist that they have been working on the development of strategies and policies to create opportunities for women to work in diverse roles in the organisation, including traditional male-dominated roles such as engineering, construction, or laboratory work. Both companies agree that policies from the headquarters also support this action in Lao PDR.

Some local tradition may promote the idea of gender-specific roles at work and discourage equal opportunity for women. Manager from mining MNC A clearly pointed that, unlike men, Lao women in his organisation may perceive some difficulties in progressing to the upper level in the organisation, due to lack of proper skills, training and time to upgrade their qualifications. Hence, companies need to integrate training into equal opportunity policies.

When Lao women work with male foreigner in the international mining MNCs, women may feel 'different' and 'inferior' to their foreign male counterparts. This circumstance can impede women to pursue leading roles and positions in the organisation since most managerial positions are dominated by male foreigners (mostly from English speaking and Western educated background). Managers from MNCs A and B agreed that statements or messages that the organisation promote equal opportunities must be sent though different communication channels.

"We need to inform women in our organisation that they are equal to their male counterparts. It can be difficult for them when they work in the international business environment where men rule." (Company A)

Both mining MNCs in this study also recognise women's role (primary carer role) as a structural barrier to their advancement. Majority of women still work in supportive roles such as cleaning, cooking and basic administrative roles. Mining MNCs agreed that they need to promote equal opportunity policies for women by eliminating traditional ideas that women can only do certain jobs. Structural barriers include the lack of gender-inclusive policy, lack of organisational support, or non-representation of women within the organisation.

Participants from both mining MNCs pointed that appropriate recruitment and promotion procedures have been implemented to promote opportunities for women to work in leadership positions, laboratory and science as well as survey. Most women who are newly recruited are aware of equal access to jobs, benefits, and services for all employees and prospective employees in the workplace. Obviously, both mining MNCs are aware of the glass-ceiling (Rutherford, 2001) and try to minimise structural barriers that impede women to grow.

"More recently an employee-initiated forum was created to look at ways to contribute to workforce diversity, initially focused on women's opportunity in the workplace."(Company A) 
For all mining MNCs in this study, equal opportunity is about ensuring that women have equal access to the rewards and opportunities available in the workplace. Manager from company A stated that women must be treated with respect and are not subject to discrimination or harassment. Both MNCs in this study identify equal opportunity as an organising principle and process that shapes social structure, identities and knowledge. The focus is then on different sets of gendering processes, including formal practices and policies; informal work practices; and symbols and images that express, legitimate and reinforce gendered divisions in organisations.

"It is a whole of organisation issue, not a human resources issue. Women must be afforded the same opportunities as men in the organisation, and must be embedded in all processes of the organisation." (Company A)

Keywords form the interviews that emphasize the concept of equal opportunity as a strategy to empower women in this industry are presented in table two.

Table 2. Some Keywords/Phrases on Promotion of Equal Opportunity

\begin{tabular}{|l|l|l|}
\hline "fair compensations" & $\begin{array}{l}\text { "fair treatment for female } \\
\text { staff" }\end{array}$ & $\begin{array}{l}\text { "open up opportunities for } \\
\text { women" }\end{array}$ \\
\hline $\begin{array}{l}\text { "training opportunities for } \\
\text { women and men" }\end{array}$ & "equality for women" & $\begin{array}{l}\text { "women to enter traditionally } \\
\text { male-dominated fields" }\end{array}$ \\
\hline $\begin{array}{l}\text { "skill building for men and } \\
\text { women" }\end{array}$ & "non-discrimination" & "gender equality" \\
\hline "ensuring fairness at work" & $\begin{array}{l}\text { "enforcement of equal } \\
\text { opportunity" }\end{array}$ & "fair promotion for women" \\
\hline
\end{tabular}

\section{Approach 3: Recognising and Celebrating the Differences}

This approach was mentioned frequently by all participants from both mining MNCs. Traditionally, we see women's disadvantage as stemming from the devaluation of the skills and attributes associated with femininity. In other words, being women is a problem from the traditional mining lens. Both mining MNCs in this study attempt to shift from a focus on eliminating difference between men and women to celebrating those differences and valuing them equally by raising awareness of how traditionally feminine activities and styles can benefit the organisation. This approach seems to fit well with the traditional Laos culture where women have long been active players in political and social arenas (Sirasoonthorn, 2013). Some keywords under this approach are listed in Table 3.

Terms such as "workplace diversity", "ethnic and gender diversity", "satisfaction and celebration", or "acceptance and celebration" were used frequently when MNCs refer to this approach. 


\section{Macrothink}

Table 3. Some Keywords/Phrases on Recognising and Celebrating Women Issues

\begin{tabular}{|c|c|c|}
\hline Femininity & $\begin{array}{l}\text { "communicating roles and } \\
\text { responsibilities of women" }\end{array}$ & $\begin{array}{l}\text { "we aimed to improve the } \\
\text { health of mothers and } \\
\text { children" }\end{array}$ \\
\hline $\begin{array}{l}\text { "celebrating workplace } \\
\text { diversity" }\end{array}$ & $\begin{array}{l}\text { "increase the knowledge and } \\
\text { skills of health for women" }\end{array}$ & "female champion" \\
\hline "women's day" & $\begin{array}{l}\text { "we value the contributions } \\
\text { from men and women" }\end{array}$ & $\begin{array}{l}\text { "We are proud that our } \\
\text { female workers speak Bru, } \\
\text { Laos and Phu Thai." }\end{array}$ \\
\hline
\end{tabular}

Both MNCs in this study believe that actions by MNCs, particular communication strategy, will promote the celebration of workplace diversity. The choice of language to communicate was also mentioned as an important part of this approach.

"Women are not the supporters but the influencers and conduit of mining business." (Company A)

Mining MNCs in this study tend to integrate and celebrate diversity in ethnic, culture, language and gender in order to imbue the organizational awareness and pride on gender equity. They adopt various strategies to celebrate women. Some of the strategies include the promotion of women's space, cultural links with women from various ethnic groups, support for mother and child health, and newsletter for women.

"In 2012, specific diversity objectives, existing employee programs and commitments to external agencies continued momentum from the previous year to support, promote and engage more Lao-nationals and females at all levels of the organisation."(Company B)

Both mining MNCs in this study also promote the concept of workforce diversity in order to improve the quantity and quality of women working in mining MNCs. In the traditional male-dominant industry such as mining, the management of gender may require extra support to promote participation of women in the workplace. Activities such as public forum, informal women club, and women's day can be useful to promote gender equity among corporate members.

One interesting aspect, as mentioned by both managers from mining $\mathrm{MNC} \mathrm{B}$, is that prior to the celebration of women in the organisation they were aware of organisational problems in the form of isolation among women from different groups, not having enough work information and resources to accomplish tasks, and being taken for granted by male colleagues. According to them, recognising and celebrating women can promote women's satisfaction and pride at workplace. 


\section{Conclusions}

The results of this study carry important implications for stakeholders in international mining industry. Policy makers and practitioners from mining MNCs addressed eclectic approaches that can be implemented to promote women in mining industry. This study highlights different approaches adopted by mining MNCs in order to empower women, and promote gender diversity in the international mining industry. It confirms, in traditionally male-dominant industry such as international mining, management requires extra and specific gender-related expert support in order to effectively promote women's participation in the workplace.

Results show that mining MNCs can promote Lao women by encouraging them to try new roles and responsibilities. By providing them skills development, training and time, Lao women can progress to various management roles in the organisation. This raises the question on how capacity building for women is made. Mining MNCs may not be able to provide exclusive capacity building programs for women. Thus, women should be encouraged to actively participate in the existing programs.

Celebration of femininity is also an important practice to empower women in mining MNCs. The celebration of diversity, not seeing gender difference as weakness, will encourage Lao women to communicate among each other. It will also form the new attitude towards women among men.

Findings from this study confirm that mining MNCs need to understand how to integrate various aspects of diversity (gender, culture, race and ethnicity) and approaches, when design policies and practices to empower women. In sum, this study supports the idea that the participative and empowerment-based method can and will be useful for mining MNCs to empower women in the organisation.

Future research should investigate proper gender approaches from various stakeholders' perspectives. Women in the organisation, clients and suppliers, community, local administrators should be included in order to understand profound local perspectives.

More importantly, it is recommended for the future study to investigate the Laotian management context that influence actions and policies of mining MNCs. Due to complex socio-political factors in the host countries, mining MNCs must be aware of some local socio-political constraints that may impede how mining MNCs promote policies on gender equity and women empowerment.

\section{Acknowledgement}

The research has been funded by the Department of Foreign Affairs and Trade through the Australian Development Awards Scheme (ADRAS) under an award titled, the Equitable Employment for Women in Mining Companies in Laos and Thailand. 


\section{References}

Bondy, K. (2008). The paradox of power in CSR: a case study on implementation. Journal of Business Ethics, 82(2), 307-323. http://dx.doi.org/10.1007/s10551-008-9889-7

Bose, S. (2004). Positioning women within the environmental justice framework: a case from the mining sector. Gender, Technology and Development, 8(3), 407-412. http://dx.doi.org/10.1177/097185240400800305

Byford, J. (2002). One day rich: community perceptions of the impact of the Placer Dome Gold mine, Misima Island In I. M. C. Rowland (Ed.), Tunnel Vision: Women, Mining and Communities. Melbourne: The University of Melbourne.

De Soto, H. (2000). The Mystery of capital. New York: Basic Books.

Eagly. A. H., \& Karau, S. J. (2002) Role congruity theory of prejudice toward female leaders. Psychological Review, 109, 573-598.

Gibson, G., \& Scoble, M. (2004). Re-gendering mining: a survey of women's career experiences in mining. CIM Bulletin, 97(1082), 55-61.

Heilman, M. E., Wallen, A. S., Fuchs, D., \& Tamkins, M. M. (2004). Penalties for success: Reactions to women who succeed at male tasks. Journal of Applied Psychology, 89, 416-427. http://dx.doi.org/10.1037/0021-9010.89.3.416

Kemp, D., \& Owen, J. (2013). Community relations in mining: core to business but not 'core business'. Resources Policy, 38(2), 523-531. http://dx.doi.org/10.1016/j.resourpol.2013.08.003

Kirton, G., \& Green, M. (2005). The dynamics of managing diversity - a critical approach. London: Elsevier.

Macintyre, M. (2011). 'Modernity, Gender and Mining: Experiences from Papua New Guinea. In K. L. Dutt (Ed.), Gendering the field: towards sustainable livelihoods for mining in mining communities. Canberra: ANU e-press.

Mercier, L., \& Gier, J. (2007). Reconsidering women and gender in mining. History Compass, 5(3), 995-1001.

Pattenden, C. (1998). Women in mining - a report to the "women in mining" taskforce [Electronic Version] Retrieved from http:/www.ausimm.com.au/content/docs/wimreport.pdf.

Robinson, K. (2002). Labour, love and loss: mining and the displacement of women's labour. In I. MacDonald (Ed.), Tunnel Vision: women, mining and communities. Melbourne: The University of Melbourne Press.

Schmidheiny, S. (2006). A view of corporate citizenship in Latin America. Journal of Corporate Citizenship, 21, 21-24. http://dx.doi.org/10.9774/GLEAF.4700.2006.sp.00004

Sirasoonthorn, P. (2013). Social Planning and Cultural Changes in Lao PDR. Bangkok: Chulalongkorn University Press. 


\section{Macrothink}

Journal of Management Research

ISSN 1941-899X 2016, Vol. 8, No. 2

Sharma, S. (2010). The impact of mining on women: lessons from the coal mining Bowen basin of Queensland, Australia. Impact Assessment and Project Appraisal, 28(3), 201-215. http://dx.doi.org/10.3152/146155110X12772982841041

Spiggle, S. (1994). Analysis and interpretation of qualitative data in consumer research. Journal of Consumer Research, 21(3), 491-503. http://dx.doi.org/10.1086/209413

Strauss, A., \& Corbin, J. (1998). Basics of qualitative Research: Techniques and Procedures for Developing Grounded Theory. London: Sage Publications.

Tallichet, S. (2000). Barriers to Women's Advancement in Underground Coal Mining. Rural Sociology, 65(2), 234-252. http://dx.doi.org/10.1111/j.1549-0831.2000.tb00027.x

Workplace Gender Equality Agency (2013). Workforce gender diversity review [Electronic Version] Retrieved from https:/www.wgea.gov.au/sites/default/files/Minerals-Council-of-Australia-(2013)-The-MCAWorkforce-Gender-Diversity-Review.pdf

Yakovleva, N., \& Vazquez-Brust, D. (2012). Stakeholder perspectives on CSR mining MNCs in Argentina. Journal of Business Ethics, 106(2), 191-211. http://dx.doi.org/10.1007/s10551-011-0989-4

\section{Copyright Disclaimer}

Copyright for this article is retained by the author(s), with first publication rights granted to the journal.

This is an open-access article distributed under the terms and conditions of the Creative Commons Attribution license (http://creativecommons.org/licenses/by/3.0/). 